Brazilian Journal

of Chemical

Engineering

ISSN 0104-6632

Printed in Brazil

www.abeq.org.br/bjche

Vol. 36, No. 03, pp. 1165 - 1173, July - September, 2019

dx.doi.org/10.1590/0104-6632.20190363s20180540

\title{
GRAPHENE OXIDE AND A GO/ZnO NANOCOMPOSITE AS CATALYSTS FOR EPOXY RING-OPENING OF EPOXIDIZED SOYBEAN FATTY ACIDS METHYL ESTERS
}

\author{
Kaline A. Wanderley ${ }^{1}$, Amanda M. Leite 2 , Gabriel Cardoso², Anderson M. Medeiros ${ }^{1}$, \\ Caroline L. Matos ${ }^{1}$, Romulo C. Dutra ${ }^{1}$ and Paulo A. Z. Suarez ${ }^{1 *}$ \\ ${ }^{1}$ Universidade de Brasília, Instituto de Química, Laboratório de Materiais e Combustíveis, Brasília, DF, Brasil. \\ ORCID: 0000-0002-3223-4501; E-mail: psuarez@unb.br - ORCID: 0000-0002-1195-3128 \\ ${ }^{2}$ Universidade de Brasília, Instituto de Química, Laboratório de Inorgânica e Materiais, Brasília, DF, Brasil.
}

(Submitted: November 12, 2018 ; Revised: January 21, 2019 ; Accepted: January 21, 2019)

\begin{abstract}
In this work, the grapheme oxide (GO) and $\mathrm{GO} / \mathrm{ZnO}$ nanocomposite were successfully obtained from the oxidation of graphite and characterized by X-ray diffraction (XRD), scanning electron microscopy (SEM), transmission electron microscopy (TEM), and thermogravimetric analysis (TGA). In the GO/ZnO nanocomposite, the GO sheets were coated with aggregated $\mathrm{ZnO}$ nanoneedles with $c a .20 \mathrm{~nm}$ of diameter. The obtained materials were used as heterogeneous catalysts for acetylation of Soybean Fatty Acids Methyl Esters (FAME), promoting the epoxy ring-opening using acetic anhydride. The epoxy ring was almost completely opened in the presence of $\mathrm{GO}$ or $\mathrm{GO} / \mathrm{ZnO}$ nanocomposites, with conversion rates up to $99 \%$ and selectivity of $\mathrm{ca}$. $90 \%$, and partially opened using only $\mathrm{ZnO}$. The $\mathrm{GO} / \mathrm{Zn}$ and $\mathrm{GO}$ catalysts were reused three times with conversion rates of $c a .85$ and $74 \%$, respectively.

Keywords: Graphene oxide; ZnO; Nanocomposite; Epoxide ring-opening; Acetylation.
\end{abstract}

\section{INTRODUCTION}

Graphene oxide (GO) and related materials such as graphene/metal oxide composites have received great attention due to their low cost, easy obtainability and compatibility with various substrates (Nie et al., 2016; Sakthivel et al., 2017). Also, synergistic effects provided by the combination of metal oxides and graphene can improve their catalytic performance compared to the individual metal oxides (Nie et al., 2016; Sakthivel et al., 2017). Among these, particularly $\mathrm{ZnO}$ (Guo et al., 2016; Nasrollahzadeh et al., 2014) has excelled because of its strong oxidizing power, non-toxic nature, low cost and its catalytic ability in both acidic and basic medium (Huang et al., 2012; Joonwichien et al., 2012).

One of the ways most widely used to obtain GO is through the Hummers method (Hummers and
Offeman, 1958), which is based on the exhaustive oxidation of graphite under strong acid conditions, using concentrated sulfuric acid, permanganate and hydrogen peroxide. In the synthesis of GO by the Hummers method, a series of functional groups containing oxygen, such as alcohols, epoxides and carboxylates, as well as a small quantity of sulfate groups, are introduced to the graphene plane, acting, thus, as Brønsted acids (Wang, et al., 2013), making these materials very active as catalysts in a myriad of organic molecule transformations (Navalón et al., 2018). Moreover, GO/metal oxide composites have the advantage of having both strong Brønsted as well as Lewis acid properties (Marso et al., 2017). Thus, the introduction of different functional groups makes GO and its composites excellent catalysts for many synthetic transformations, such as sulfide, thiol

\footnotetext{
* Corresponding author: Paulo A. Z. Suarez - E-mail: psuarez@unb.br
} 
(Dreyer et al., 2010), C-H bond (Jia et al., 2011), alcohol and alkene oxidation (Dreyer et al., 2010), hydrogenation of nitrobenzene (Gao et al., 2011) and epoxide ring opening (Acocella et al., 2016; Dhakshinamoorthy et al., 2012). These solid materials can act as heterogeneous acid catalysts, which prevent the dispersion in water, enhance the mechanical properties and interact easily with nucleophilic centers (Cheng et al., 2016; Garg et al., 2014).

Epoxidation followed by a ring-opening reaction, particularly of vegetable oils or Fatty Acids Methyl Esters (FAME), has been studied with the intent of utilizing the epoxidized products as intermediates for polymer preparations (Diciccio and Coates, 2011; Nicolau et al., 2012), such as polyesters, polyurethanes, biolubricants (Sharma et al., 2015; Sharma and Dalai, 2013), and epoxy resins (Samper et al., 2012), or as stabilizer for plastics. FAME, produced from many different sources (Ruschel et al., 2016), have been used as biofuel (biodiesel) to partially or completely substitute diesel fuel. Because of the poor low temperature performance, and low oxidative and thermal stability of some vegetable oils and their derived FAME, epoxidation was also suggested to improve these undesired properties (Biresaw and Bantchev, 2013; Wang et al., 2013).

After the vegetable oil or FAME is epoxidized, the first modification step performed is the oxirane ringopening, followed by an acylation step. Recent studies have shown that ring-opening, esterification and/or acetylation result in: $i$ ) improved viscosity index; ii) better low temperature flow properties; iii) increased thermal and oxidative stability; iv) lower coefficients of friction, and v) enhanced lubricity characteristics (McNutt and He, 2016). Nevertheless, epoxy ringopening, using acetic anhydride, is performed with strong acid or basic catalysts, excess of reagents, high temperatures, and long times, as well as high mass fractions of heterogeneous catalysts. In this context, the relatively acid catalysts $\mathrm{GO}$ and $\mathrm{GO} / \mathrm{ZnO}$ were used in the ring-opening reaction of epoxidized soybean FAME.

\section{EXPERIMENTAL SECTION}

\section{Chemicals and Materials}

Synthetic graphite powder $(<20$ micron), zinc oxide $(\mathrm{ZnO})$, anhydrous $\mathrm{MgSO}_{4}$ and basic alumina $\left(\mathrm{Al}_{2} \mathrm{O}_{3}\right)$ were purchased from Aldrich; potassium permanganate $\left(\mathrm{KMnO}_{4}\right)$ from Merck; 98\% sulfuric acid $\left(\mathrm{H}_{2} \mathrm{SO}_{4}\right), 30 \%$ hydrogen peroxide $\left(\mathrm{H}_{2} \mathrm{O}_{2}\right)$, zinc chloride $\left(\mathrm{ZnCl}_{2}\right)$, sodium hydroxide $(\mathrm{NaOH})$, acetic anhydride, and absolute ethanol were purchased from Vetec. Commercial refined soybean oil was purchased from a local store. 99\% methanol $(\mathrm{MeOH})$ was purchased from Cromaline. Potassium hydroxide
$(\mathrm{KOH})$ and sodium bicarbonate $\left(\mathrm{NaHCO}_{3}\right)$ were purchased from Synth. 85\% Formic acid ( $\mathrm{HCOOH})$ was purchased from Dinâmica and the Nitrogen Gas $\left(\mathrm{N}_{2}\right)$ was purchased from White Martins. All chemicals were analytical grade and were used as received without further purification.

\section{Synthesis of Graphene Oxide (GO) and GO/ZnO Nanocomposite}

The graphene oxide (GO) was prepared from graphite powder using a modified (Huang et al., 2012; Min and Lu, 2011) Hummers method (Hummers and Offeman, 1958). $\mathrm{H}_{2} \mathrm{SO}_{4}(46 \mathrm{~mL})$ and graphite $(2 \mathrm{~g})$ were stirred vigorously in an ice bath, $\mathrm{KMnO}_{4}(6 \mathrm{~g})$ was slowly added and stirred for about $30 \mathrm{~min}$. Water (50 $\mathrm{mL})$ was added and stirred. Finally, more water $(300$ $\mathrm{mL}$ ) was added, followed by the slow addition of $\mathrm{H}_{2} \mathrm{O}_{2}$ $(10 \mathrm{~mL})$. The dispersion obtained was centrifuged at $6000 \mathrm{rpm}$ for $15 \mathrm{~min}$ and rinsed repeatedly with water to remove the remaining salt until $\mathrm{pH} \mathrm{7,} \mathrm{washed} \mathrm{with}$ ethanol and dried at room temperature (Zhang et al., 2011).

The synthesis of $\mathrm{GO} / \mathrm{ZnO}$ nanocomposite was based on Li et al. (2012), in which $0.1 \mathrm{~g}$ of GO was dispersed in $40 \mathrm{~mL}$ of water by ultra-sonication. $\mathrm{ZnCl}_{2}$ (1.0 mmol) and $\mathrm{NaOH}(10.0 \mathrm{mmol})$ were successively dissolved in the GO suspension. The mixture was stirred for $6 \mathrm{~h}$ at $90{ }^{\circ} \mathrm{C}$ and then cooled to room temperature. The composite obtained was filtered, washed with water and ethanol, and dried at room temperature.

\section{FAME Epoxidation and Ring-Opening Reactions}

The soybean FAME was obtained by transesterification, as described in the literature (Oliveira et al., 2006; Ramalho et al., 2014), with a mass ratio of 6.42:57.5:1 (soybean oil:MeOH:KOH), in which $\mathrm{KOH}$ was completely dissolved in $\mathrm{MeOH}$ under magnetic stirring and nitrogen atmosphere in a reactor. Then, the dried soybean oil was added into the reactor and the mixture was maintained under stirring for $3 \mathrm{~h}$ at room temperature. The final product was washed repeatedly with distilled water, dried with anhydrous $\mathrm{MgSO}_{4}$ under vacuum, filtered on a basic alumina column under nitrogen atmosphere and stored at below $0{ }^{\circ} \mathrm{C}$, to prevent the oxidation of the unsaturation.

Soybean FAME (ca. $30 \mathrm{~g}$ ) was placed in a reflux system at $60{ }^{\circ} \mathrm{C}$ and a mixture of $\mathrm{H}_{2} \mathrm{O}_{2}$ and formic acid was slowly added to the reaction, with a mass ratio of 1.42:1.92:1.88 (Soybean FAME:Formic Acid:Hydrogen Peroxide); then the temperature of the system was increased to $80{ }^{\circ} \mathrm{C}$ and the reaction refluxed for $5 \mathrm{~h}$. After cooling, the system was washed repeatedly with distilled water, dried with anhydrous $\mathrm{MgSO}_{4}$ under vacuum, filtered on a basic alumina 
column under nitrogen atmosphere and stored at below $0{ }^{\circ} \mathrm{C}$ (Campanella et al., 2008).

After the FAME epoxidation, the oxirane ring opening was performed by acetylation reaction (Oliveira et al., 2017), in which FAME epoxide $(1,0 \mathrm{~g})$ was mixed with acetic anhydride $(1,0 \mathrm{~g})$ and different amounts of $\mathrm{GO}, \mathrm{ZnO}$ and $\mathrm{GO} / \mathrm{ZnO}$ catalysts were added to the mixture under stirring in a Schlenk tube at $120{ }^{\circ} \mathrm{C}$ for $12 \mathrm{~h}$ or $24 \mathrm{~h}$. The modified FAME was washed with ethanol and centrifuged at $6000 \mathrm{rpm}$ for $15 \mathrm{~min}$, then dried under vacumm for $24 \mathrm{~h}$. The reusability of $\mathrm{GO}$ and $\mathrm{GO} / \mathrm{ZnO}$ catalysts was measured in the oxirane ring-opening of epoxidized soybean FAME; three cycles of the catalytic experiment for each catalyst were carried out in optimal conditions. In all recycling experiments, the reaction mixture was centrifuged after the reaction in order to separate the catalysts. The $\mathrm{GO}$ and $\mathrm{GO} / \mathrm{ZnO}$ catalysts were washed with water and dried at $50{ }^{\circ} \mathrm{C}$ before being reused in the reaction.

\section{General Characterization}

GO and $\mathrm{GO} / \mathrm{ZnO}$ nanocomposites were characterized by X-ray powder diffraction collected at room temperature using a Bruker D8 with copper rotating anode $\left(\lambda_{\mathrm{ka} 1}=1.5404 \AA, \lambda_{\mathrm{ka} 2}=1.5444 \AA\right.$, $\mathrm{I}_{\alpha 2} /$ $\left.\mathrm{I}_{\alpha 1}=0.5\right)$ sealed-tube fine focus X-ray source. Intensity data were collected in step scanning mode ranging from 5 to $90^{\circ}(2 \theta)$, step size of $0.01^{\circ}$, Soller slit with $2.5^{\circ}$ divergence, scattering slit of $2.5^{\circ}$ and receiving slit of $0.3 \mathrm{~mm}$. Scanning Electron Microscopy (SEM) images were collected using a JEOL scanning electron microscope (JSM-6610) working at $15 \mathrm{kV}$. Samples were prepared by deposition on aluminum sample holders followed by carbon coating and a later gold coating (ca. $20 \mathrm{~nm})$ to $5 \mathrm{~mA}$. Transmission Electron Microscopy (TEM) images were obtained using a JEOL 1011 transmission electron microscope. Samples were diluted in ethanol, deposited on a copper grid, and dried at room temperature. The FAME products were analyzed by infrared spectroscopy using a FTIR spectrometer model IR Prestige from Shimadzu, with ATR Miracle cell and by ${ }^{1} \mathrm{H}$ nuclear magnetic resonance spectroscopy $\left(600 \mathrm{MHz}, \mathrm{CDCl}_{3}\right)$, using a Bruker, model Magneto Ascend 600 with Console Avance III HD.

\section{RESULTS AND DISCUSSION}

\section{Characterization of GO and GO/ZnO Nanocomposites}

Oxidation of graphite to graphene using a modified Hummers method was evaluated by X-ray diffraction (XRD). The XRD patterns (Figure 1) show that after oxidation, the diffraction peaks of graphite in $2 \theta=26.6^{\circ}$ $\left(\mathrm{d}_{\mathrm{hkl}}=002\right)$ and $2 \theta=54.4^{\circ}\left(\mathrm{d}_{\mathrm{hkl}}=004\right)$ disappeared,

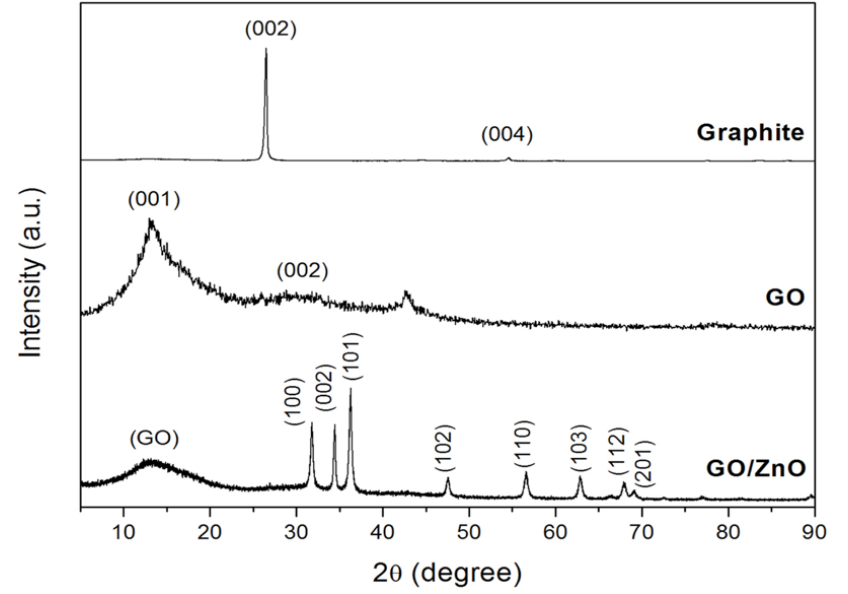

Figure 1. XRD Patterns of graphite, graphene oxide (GO) and $\mathrm{GO} / \mathrm{ZnO}$ nanocomposite.

while for graphene a broad and characteristic peak appeared at a lower diffraction angle in $2 \theta=13.1^{\circ}\left(\mathrm{d}_{\mathrm{hkl}}\right.$ $=001)$. The absence of the characteristic diffraction peaks of graphite confirmed the obtainment of graphene oxide (Huang et al., 2012). Moreover, the introduction of oxygen-containing functional groups on the surfaces of the graphite sheet induced an interplanar distance in GO of ca. $6.75 \AA$, using Bragg's law $(2 \mathrm{~d} \sin \theta=\mathrm{n} \lambda)$ (Sheng et al., 2013), that is much larger than of graphite $(3.35 \AA)$, as described in the literature (Bian et al., 2009a; Bian et al., 2009b). The diffraction peaks of the $\mathrm{GO} / \mathrm{ZnO}$ nanocomposite are like those of hexagonal phase wurtzite $\mathrm{ZnO}$ (data 82028-ICSD); as well the characteristic diffraction peak of graphene was observed in $2 \theta=13.1^{\circ}\left(\mathrm{d}_{\mathrm{hkl}}=001\right)$, demonstrating that the $\mathrm{GO} /$ $\mathrm{ZnO}$ nanocomposite was obtained successfully.

Microstructures and morphologies of GO and the $\mathrm{GO} / \mathrm{ZnO}$ nanocomposite were evaluated by scanning electron microscopy (SEM) and transmission electron microscopy (TEM). In the SEM image of GO (Figure 2 ), the stacked structure of graphene sheets can be seen with thin layers arranged like waves or wrinkles in the surface, whereas for the $\mathrm{GO} / \mathrm{ZnO}$ nanocomposite the presence is observed of small particles of $\mathrm{ZnO}$ deposited on and between the GO sheet surfaces, as can be best seen in the TEM images (Figure 3).

In the TEM and HR-TEM images (Figure 3) it is possible to distinguish the light-gray thin films, that are the GO sheets, from the dark regions on the

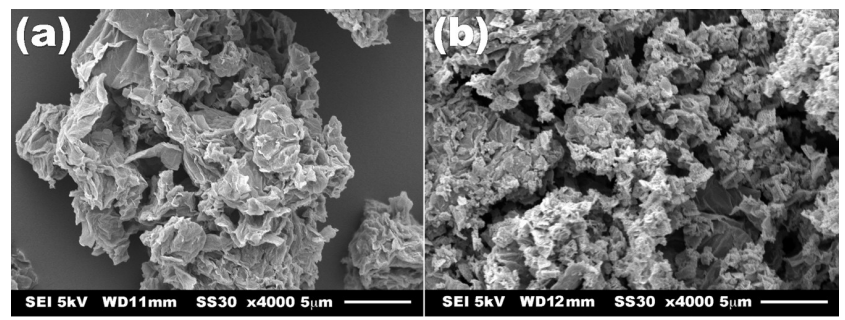

Figure 2. SEM images of (a) $\mathrm{GO}$ and (b) $\mathrm{GO} / \mathrm{ZnO}$ nanocomposite. 


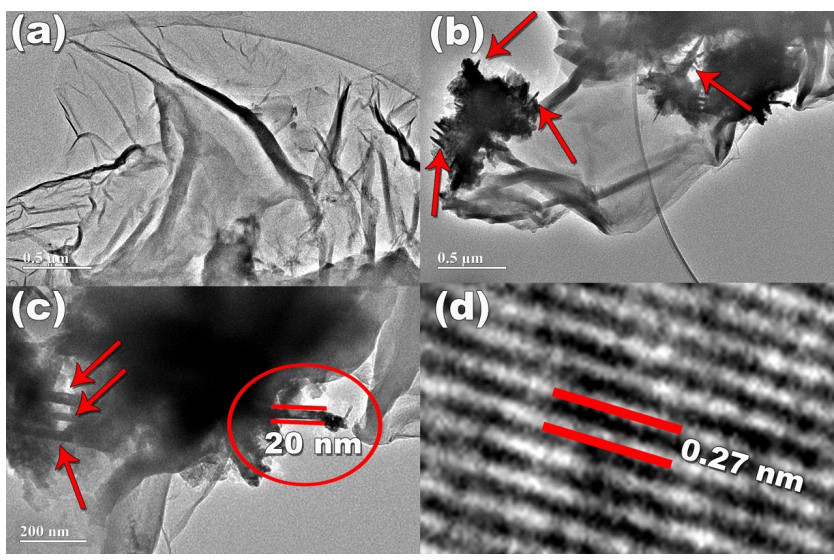

Figure 3. HR-TEM images of (a) $\mathrm{GO}$, (b) $\mathrm{GO} / \mathrm{ZnO}$, (c) $\mathrm{ZnO}$ nanoneedles are indicated by red arrows and (d) interplanar distance of $\mathrm{ZnO}$ nanoparticle.

$\mathrm{GO}$ background that are due to the presence of $\mathrm{ZnO}$ nanoparticles. The GO sheets were decorated with aggregated $\mathrm{ZnO}$ nanoneedles with $c a .20 \mathrm{~nm}$ of diameter, in which the $\mathrm{ZnO}$ nanoparticles were mainly located at the edge of the GO sheets. The interplanar distance found in the HR-TEM was $c a .0 .272 \mathrm{~nm}$, which corroborates with data of interplanar spacing of $\mathrm{ZnO}$ obtained by the XRD pattern of $c a .2 .47 \AA$, using Bragg's law $(2 \mathrm{~d} \sin \theta=\lambda)$ in $2 \theta=36.31^{\circ}\left(\mathrm{d}_{\mathrm{hkl}}=101\right)$, Figure 1.
Thermogravimetric curves show the thermal stability of $\mathrm{GO}$ and $\mathrm{GO} / \mathrm{ZnO}$ (Figure 4). The highest rate of mass loss of GO occurred between 100 and 300 ${ }^{\circ} \mathrm{C}$, indicating the release of $\mathrm{CO}, \mathrm{CO}_{2}$ and vapors from the most labile functional groups during pyrolysis. The differential thermal analysis (DTA) curve of GO/ $\mathrm{ZnO}$ presents an exothermic loss due to liberation of $\mathrm{CO}, \mathrm{CO}_{2}$ and vapors due to the presence of $\mathrm{GO}$ in the nanocomposite. At higher temperatures, weight loss continues up to $500{ }^{\circ} \mathrm{C}$, which could be associated to decomposition of reminiscent $\mathrm{Zn}(\mathrm{OH})_{2}$ (Moharram et al., 2014). Above $700^{\circ} \mathrm{C}$, the DTA curve of $\mathrm{GO} / \mathrm{ZnO}$ has a prominent endothermic peak which can be attributed to the structural reorganization of $\mathrm{ZnO}$, reduction and sublimation of the Zn (Anthrop and Searcy, 1964), and the crystallization of some amorphous carbon (Araújo et al., 2009). These results agree with XRD pattern data, confirming the obtaining of the nanocomposite and, moreover, showing their thermal stability.

\section{Catalytic Performance of GO and $\mathrm{GO} / \mathrm{ZnO}$ nanocomposite}

Soybean FAME were obtained by transesterification as described in a previous work (Ramalho et al., 2014), using $\mathrm{KOH}$, methanol and dried soybean oil. The final product was $c a .99 .3 \%$ pure in FAME, measured by HPLC using a method previously described (Carvalho

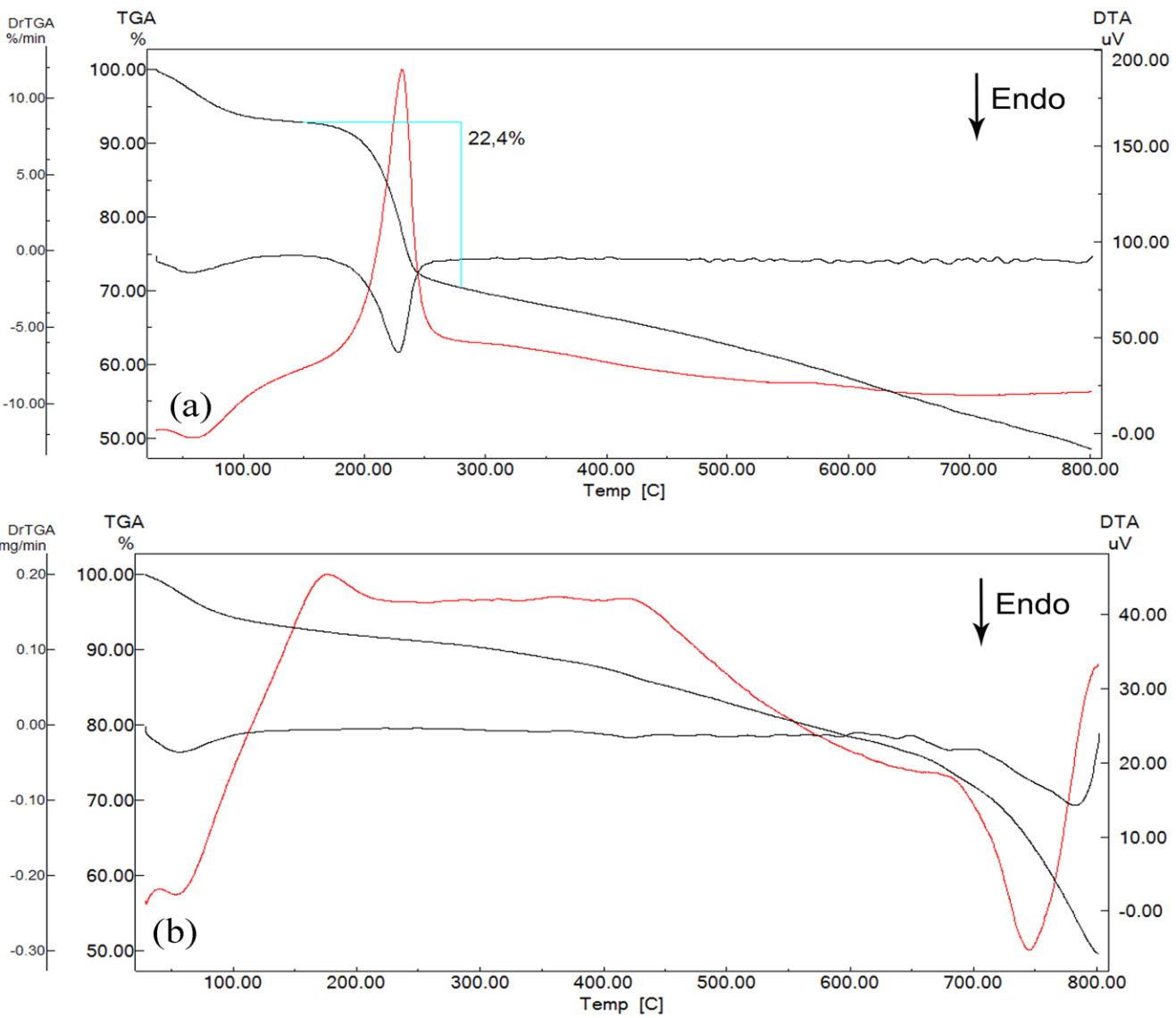

Figure 4. Thermogravimetric curves of (a) $\mathrm{GO}$ and (b) $\mathrm{GO} / \mathrm{ZnO}$. 
et al., 2012). Moreover, soybean FAME and epoxide soybean FAME were evaluated by FTIR and ${ }^{1} \mathrm{H}$ NMR spectroscopies (Figure 5). The main characteristic of the soybean FAME in the FTIR spectrum is the presence of an absorption band attributed to $\mathrm{sp}^{2}$ $\mathrm{C}-\mathrm{H}$ groups with a stretch at $3010 \mathrm{~cm}^{-1}$. There are characteristic peaks in the ${ }^{1} \mathrm{H}$ NMR spectrum with chemical shifts in the region of $5.2-5.6 \mathrm{ppm}$ ( $\mathrm{Y}$ in Figure $5 \mathrm{~b}$ ), which are attributed to the hydrogens adjacent to the unsaturation.

When the epoxide soybean FAME is formed, the characteristic band in the FTIR spectrum of $\mathrm{sp}^{2} \mathrm{C}-\mathrm{H}$ of the FAME disappears and new ones arise at $c a .823$ and $842 \mathrm{~cm}^{-1}$ referring to $\mathrm{C}-\mathrm{O}$ stretches present in the oxirane ring of the epoxy group. The ${ }^{1} \mathrm{H}$ NMR spectrum shows that the typical signals of the hydrogen adjacent to the FAME unsaturation bond at $5.2-5.6 \mathrm{ppm}(\mathrm{Y}$ in Figure 5b) vanished. Concomitantly, the hydrogen signals of the epoxide ring arose between $2.8-3.2$ ppm, Z in Figure 5b (Jacintho et al., 2009; Oliveira et al., 2017). The conversion of soybean FAME to epoxide soybean FAME $\left(\mathrm{Y}_{\text {initial }}-\mathrm{Y}_{\text {final }} / \mathrm{Y}_{\text {initial }} \times 100\right)$ was $c a .98 .4 \%$ and the selectivity of the epoxidation reaction $(\mathrm{Z} / \mathrm{Y} \times 100)$ was $c a .79 .8 \%$, because the $2 \mathrm{H}$ of $\mathrm{Y}$ form $2 \mathrm{H}$ of $\mathrm{Z}$, in which $\mathrm{Y}$ is the amount of hydrogen in the peak area from $5.2-5.6 \mathrm{ppm}$ and $Z$ is the amount of unshielded hydrogen in the peak area

(a)

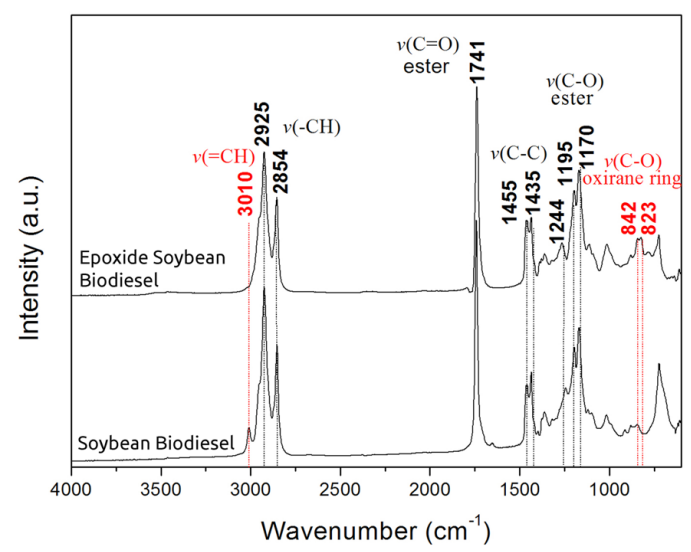

(b)
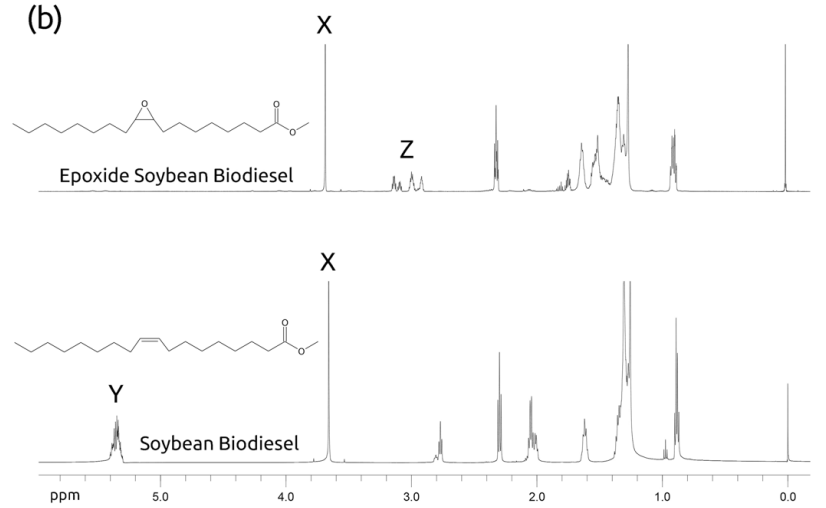

Figure 5. (a) FTIR and (b) ${ }^{1} \mathrm{H}$ NMR spectra of the soybean FAME and epoxidized soybean FAME. from $2.8-3.2 \mathrm{ppm}$. According to the literature, it is possible to identify the opening of the epoxide by the integration of the relative areas in ${ }^{1} \mathrm{H}$ MNR spectra (Aerts and Jacobs, 2004). The peak at ca. $3.6 \mathrm{ppm}$ (X in Figure 5b), corresponding to $\mathrm{OCH}_{3}$ hydrogens of the terminal ester groups of the FAME carbon chain, was used as internal standard for conversion and selectivity calculation, since it does not change in the reaction.

The epoxidation was performed aiming at posterior epoxy ring-opening with acetic anhydride in the presence of $\mathrm{GO}$ and $\mathrm{GO} / \mathrm{ZnO}$ catalysts, resulting in an acetylated FAME, the di-acetyl soybean FAME (Figure 6). The acetylation products were analyzed by FTIR and ${ }^{1} \mathrm{H}$ NMR spectroscopies.

The disappearance of characteristic vibrational modes of epoxy at $c a .823$ and $842 \mathrm{~cm}^{-1}$ in the FTIR spectrum (Figure 7) evidences the oxirane ring-opening, as well as the absorption band at $c a$. $1234 \mathrm{~cm}^{-1}$ related to the acetyl groups present in the structure (Azeh et al., 2013; Wang et al., 2016). Another important indication of the addition of acetic anhydride in the modified FAME is the presence of the vibrational mode at $c a .1738 \mathrm{~cm}^{-1}$ related to $\mathrm{C}=\mathrm{O}$ stretches.

The epoxy ring-opening reaction was evaluated by ${ }^{1} \mathrm{H}$ NMR spectroscopy by the decrease of the characteristic peaks of the protons adjacent to the oxirane ring at $c a .2 .8$ at $3.2 \mathrm{ppm}$ (Scala and Wool, 2002) (Figure 8). The conversion of the epoxy ringopening reaction was calculated, as before, using the relation $\left(Z_{\text {initial }}-Z_{\text {final }}\right) / Z_{\text {initial }} \times 100$ and the selectivity of the acetylation reaction by $\mathrm{A} / 3 \mathrm{Z} \times 100$, since the $2 \mathrm{H}$ of $\mathrm{Z}$ form $6 \mathrm{H}$ of $\mathrm{A}$ (Figure 8), an unshielded methyl adjacent to a carbonyl of the di-acetyl group, in which $\mathrm{A}$ is the amount of hydrogen in the peak area around $2.0 \mathrm{ppm}$ and $\mathrm{Z}$ is the amount of unshielded hydrogen in the peak area from $2.8-3.2 \mathrm{ppm}$. Thus, the peak at
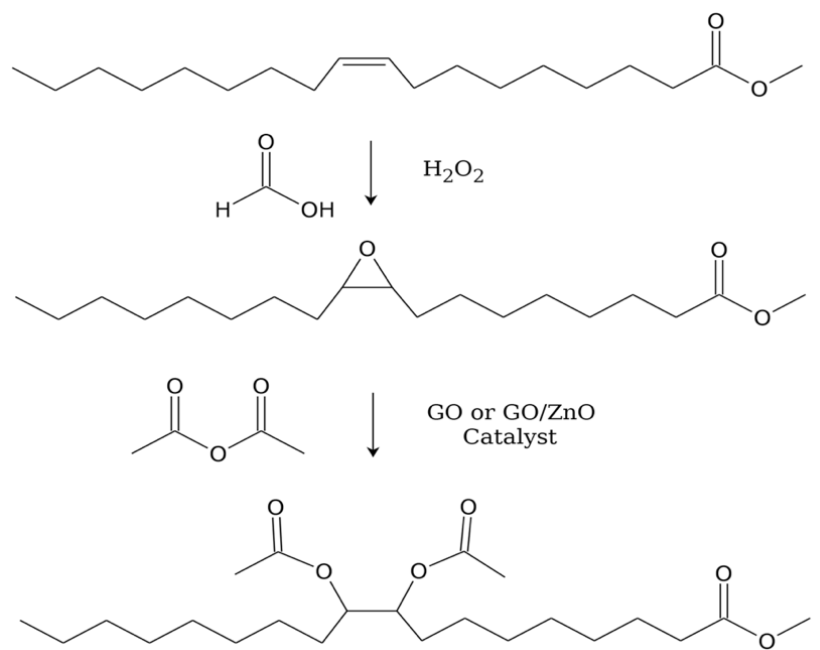

Figure 6. Epoxidation and ring-opening of epoxidized soybean FAME. 


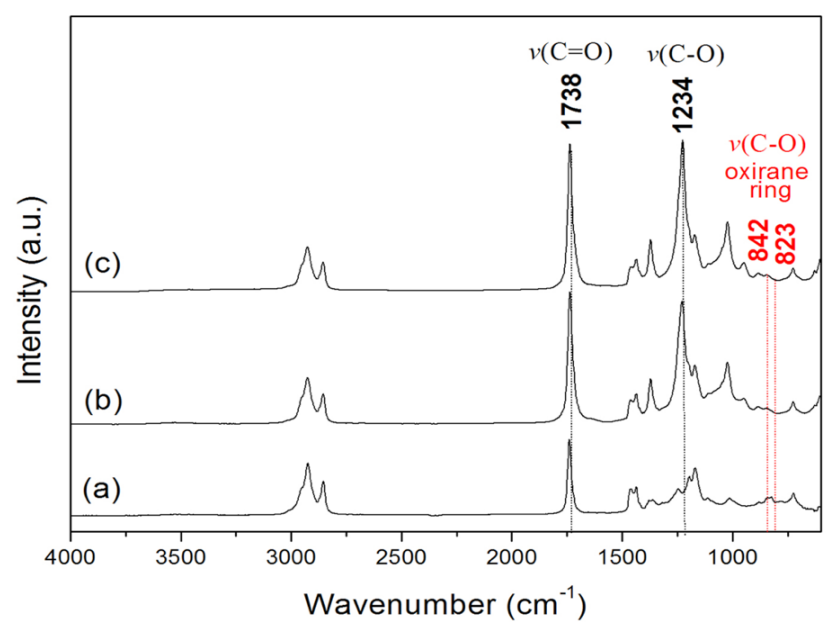

Figure 7. FTIR Spectra of (a) Epoxide Soybean FAME and oxirane ring-opening reaction of the epoxidized soybean FAME performed with acetic anhydride in the presence of (b) $\mathrm{GO}$ and (c) $\mathrm{GO} / \mathrm{ZnO}$ catalysts.

ca. $3.6 \mathrm{ppm}$ (X in Figure 8), corresponding to $\mathrm{OCH}_{3}$ hydrogens of the terminal ester groups of the FAME carbon chain, was also used as internal standard, because to it does not change during the reaction.

Acetic anhydride represents a relatively weak nucleophile. Therefore, the reaction usually demands high acidity/alkalinity, excess reagent, or long reaction times and high temperatures (Madankar et al., 2013). The $\mathrm{GO}$ and $\mathrm{GO} / \mathrm{ZnO}$ catalysts were thermally stable around $150{ }^{\circ} \mathrm{C}$ (Figure 4); thus, the acetylation reaction was performed at $120^{\circ} \mathrm{C}$ and 12 or $24 \mathrm{~h}$ using 1 or 10 $\% \mathrm{w} / \mathrm{w}$ of catalysts (Table 1 ). Reactions carried out at lower temperatures $\left(80{ }^{\circ} \mathrm{C}\right.$ or $\left.100{ }^{\circ} \mathrm{C}\right)$ and for a short time (until $12 \mathrm{~h}$ ) present low conversion yields (ca. 30 to $45 \%$ ). The epoxy ring was almost completely open in the presence of $\mathrm{GO} / \mathrm{ZnO}$ nanocomposite catalyst ( $c a$. $98.6 \%$ ), partially open using only GO (ca. 88.2\%), and poorly opened using only $\mathrm{ZnO}(\mathrm{ca} .59 .6 \%)$ as catalysts, at optimal conditions, at $120^{\circ} \mathrm{C}$ for $24 \mathrm{~h}$. The selectivity was increased when the amount of catalyst was enhanced to $10 \% \mathrm{w} / \mathrm{w}$, being still a low amount of catalyst, mainly $\mathrm{ZnO}$ in the $\mathrm{GO} / \mathrm{ZnO}$ nanocomposite, comparing with works in the literature with similar results using $15 \%$ $\mathrm{w} / \mathrm{w}$ of catalyst for epoxy ring-opening in the acetylation reaction (Oliveira et al., 2017). The results are even better when the amount of GO was enhanced to $20 \%$ $\mathrm{w} / \mathrm{w}$, showing the efficiency of GO as acid catalyst.

\section{Catalytic Recycle}

The reusability of GO and GO/ZnO nanocomposite catalysts were performed in the epoxy ring-opening of epoxided FAME (Figure 9), showing activities up to $85 \%$ in all recycle reactions. There was a small mass loss, but after three cycles the catalytic activity was almost completely preserved. XRD analysis (Figure $9 \mathrm{~b}$ ) indicates the leaching of the $\mathrm{ZnO}$ nanoparticles
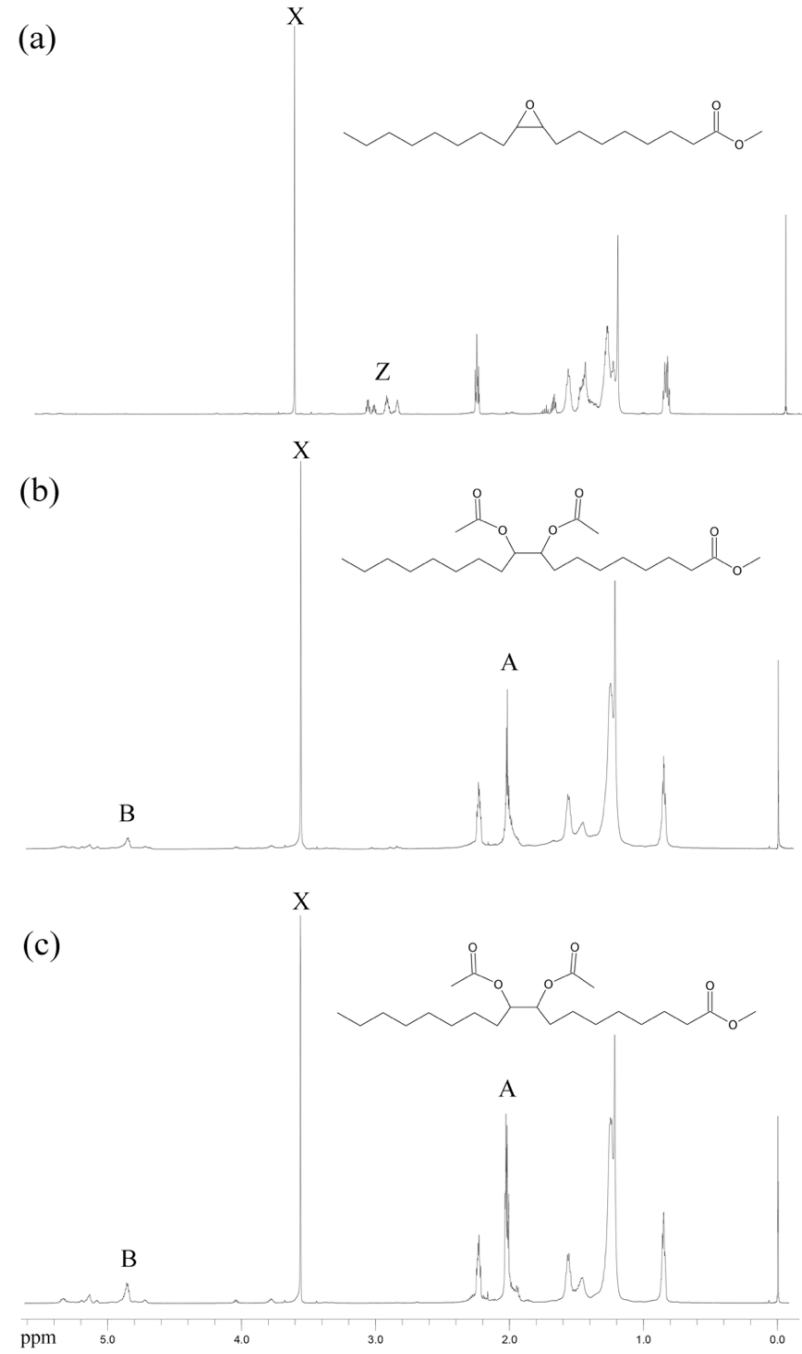

Figure 8. ${ }^{1} \mathrm{H}$ MNR spectra of (a) Epoxide Soybean FAME and oxirane ring-opening reaction of the epoxidized FAME performed with acetic anhydride in the presence of (b) $\mathrm{GO}$ and (c) $\mathrm{GO} / \mathrm{ZnO}$ catalysts.

Table 1. Conversion and selectivity of epoxy ringopening in the acetylation reaction, in the presence of $\mathrm{GO}, \mathrm{ZnO}$ and $\mathrm{GO} / \mathrm{ZnO}$ catalysts at $120^{\circ} \mathrm{C}$ for different times and amounts of catalysts.

\begin{tabular}{ccccc}
\hline Catalyst & \% w/w & $\begin{array}{c}\text { Time } \\
(\mathrm{h})\end{array}$ & $\begin{array}{c}\text { Conversion } \\
(\%)\end{array}$ & $\begin{array}{c}\text { Selectivity } \\
(\%)\end{array}$ \\
\hline- & 0 & 12 & 8.26 & 22.8 \\
- & 0 & 24 & 10.3 & 28.9 \\
$\mathrm{GO}$ & 1 & 12 & 75.1 & 54.9 \\
$\mathrm{GO}$ & 1 & 24 & 81.4 & 61.4 \\
$\mathrm{GO}$ & 10 & 12 & 83.3 & 68.8 \\
$\mathrm{GO}$ & 10 & 24 & 88.2 & 75.4 \\
$\mathrm{GO}$ & 20 & 24 & 96.3 & 88.1 \\
$\mathbf{Z n O}$ & $\mathbf{1}$ & $\mathbf{1 2}$ & $\mathbf{5 0 . 9}$ & $\mathbf{4 9 . 2}$ \\
$\mathbf{Z n O}$ & $\mathbf{1}$ & $\mathbf{2 4}$ & $\mathbf{4 9 . 8}$ & $\mathbf{5 0 . 3}$ \\
$\mathbf{Z n O}$ & $\mathbf{1 0}$ & $\mathbf{1 2}$ & $\mathbf{5 6 . 3}$ & $\mathbf{4 7 . 6}$ \\
$\mathbf{Z n O}$ & $\mathbf{1 0}$ & $\mathbf{2 4}$ & $\mathbf{5 9 . 6}$ & $\mathbf{5 7 . 1}$ \\
$\mathrm{GO} / \mathrm{ZnO}$ & 1 & 12 & 95.9 & 71.2 \\
$\mathrm{GO} / \mathrm{ZnO}$ & 1 & 24 & 96.3 & 73.8 \\
$\mathrm{GO} / \mathrm{ZnO}$ & 10 & 12 & 98.4 & 85.4 \\
$\mathrm{GO} / \mathrm{ZnO}$ & 10 & 24 & 98.6 & 89.5 \\
\hline
\end{tabular}


(a)

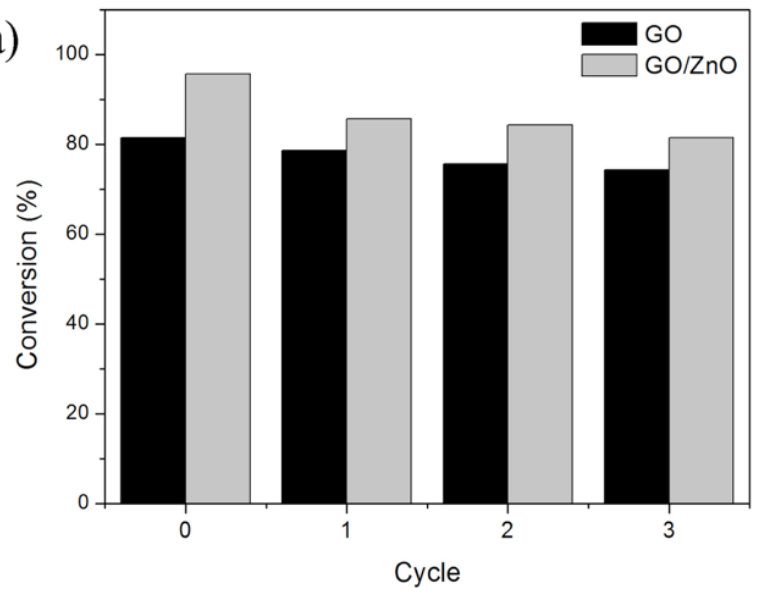

(b)

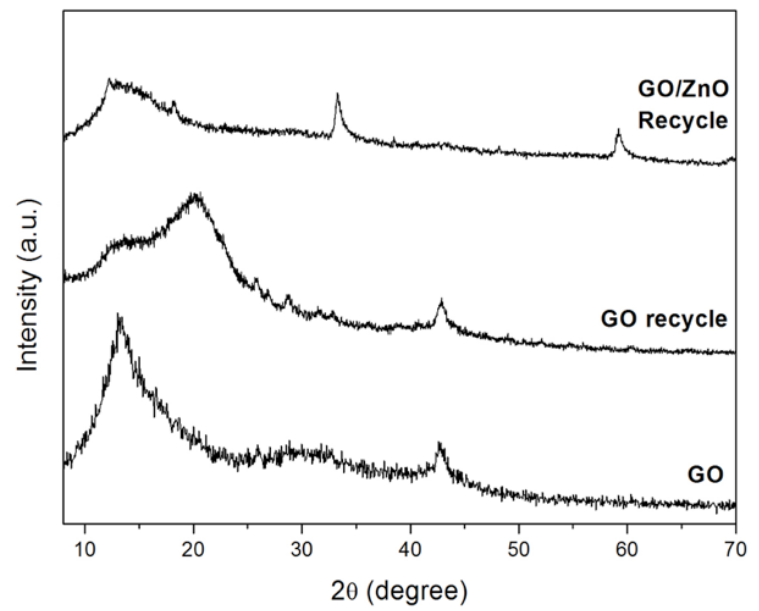

Figure 9. (a) Recycle reactions of ring-opening of epoxidized soybean FAME using $\mathrm{GO}$ and $\mathrm{GO} / \mathrm{ZnO}$ catalysts and (b) XRD patterns of $\mathrm{GO}$ and $\mathrm{GO} / \mathrm{ZnO}$ after recycling reactions comparing with $\mathrm{GO}$ before reaction.

from the composite, resulting in a reduction of $11 \%$ in the reaction yield upon the third recycle. Noteworthily, these results are similar to those presented by GO (reaction yield of $c a .10 \%$ ) under the same recycle regime. Thus, the heterogeneous acid catalysts herein presented were not deactivated during the acetylation reaction, presenting excellent activity/cycle, thermal stability around $120{ }^{\circ} \mathrm{C}$ and water tolerance. In addition, both heterogeneous catalysts can be easily separated from the reaction medium.

\section{CONCLUSIONS}

$\mathrm{GO}$ and the $\mathrm{GO} / \mathrm{ZnO}$ nanocomposite were synthesized, characterized and used as a heterogeneous catalytic system for the acetylation of soybean FAME. Indeed, $\mathrm{GO}$ and $\mathrm{GO} / \mathrm{ZnO}$ were active for epoxy ring-opening with acetic anhydride, achieving great conversion rates and selectivity. The best results were obtained at $120{ }^{\circ} \mathrm{C}$ for $24 \mathrm{~h}$. The $\mathrm{GO} / \mathrm{ZnO}$ nanocomposite showed better performance than GO catalyst and the selectivity was enhanced when the amount of catalyst was increased. The epoxy ring was almost completely opened in the presence of GO or $\mathrm{GO} / \mathrm{ZnO}$ nanocomposite and partially opened using only $\mathrm{ZnO}$ as catalysts, with conversion up to $c a$. $99 \%$ and selectivity of $c a .90 \%$, showing that the proposed reaction could be easily performed using $\mathrm{GO}$ or $\mathrm{GO} /$ $\mathrm{ZnO}$ catalysts. The catalytic activities in all recycle reactions were practically preserved with activities up to $85 \%$. Although the activity of $\mathrm{GO} / \mathrm{ZnO}$ catalyst decreased, probably due to the $\mathrm{ZnO}$ nanoparticle leaching, the GO catalyst showed stable catalytic activity and does not undergo deactivation during the acetylation reaction. Therefore, the $\mathrm{GO}$ and $\mathrm{GO} / \mathrm{ZnO}$ heterogeneous catalysts present good conversion and selectivity for epoxy ring-opening in the acetylation reaction of epoxide soybean FAME with ease of separation, excellent activity, thermal stability at 120 ${ }^{\circ} \mathrm{C}$, being great catalysts for these reactions.

\section{ACKNOWLEDGMENTS}

Authors acknowledge CAPES, CNPq and FAP-DF for financial support and fellowships.

\section{REFERENCES}

Acocella, M.R., Corcione, C.E., Giuri, A., Maggio, M., Maffezzoli, A., Guerra, G. Graphene oxide as a catalyst for ring opening reactions in amine crosslinking of epoxy resins. RSC Adv., 6, 2385823865 (2016). https://doi.org/10.1039/C6RA00485G

Aerts, H.A.J., Jacobs, P.A. Epoxide yield determination of oils and fatty acid methyl esters using $1 \mathrm{H}$ NMR. J. Am. Oil Chem. Soc., 81, 841-846 (2004). https:// doi.org/10.1007/s11746-004-0989-1

Anthrop, D.F., Searcy, A.W. Sublimation and Thermodynamic Properties of Zinc Oxide. J. Phys. Chem., 68, 2335-2342 (1964). https://doi. org $/ 10.1021 / \mathrm{j} 100790 \mathrm{a} 052$

Araújo, J.V.D.S., Ferreira, R.V., Yoshida, M.I., Pasa, V.M.D. Zinc nanowires synthesized on a large scale by a simple carbothermal process. Solid State Sci., 11, 1673-1679 (2009). https://doi.org/10.1016/j. solidstatesciences.2009.05.034

Azeh, Y., Olatunji, G.A., Mohammed, C., Mamza, P.A. Acetylation of wood flour from four wood species grown in Nigeria using vinegar and acetic anhydride. Int. J. Carbohydr. Chem., 2013, 1-6 (2013). https://doi.org/10.1155/2013/141034

Bian, J., Xiao, M., Wang, S., Wang, X., Lu, Y., Meng, Y. Highly effective synthesis of dimethyl carbonate from methanol and carbon dioxide using a novel copper-nickel/graphite bimetallic nanocomposite catalyst. Chem. Eng. J., 147, 287-296 (2009a). https://doi.org/10.1016/j.cej.2008.11.006 
Bian, J., Xiao, M., Wang, S.J., Lu, Y.X., Meng, Y.Z. Graphite oxide as a novel host material of catalytically active $\mathrm{Cu}-\mathrm{Ni}$ bimetallic nanoparticles. Catal. Commun., 10, 1529-1533 (2009b). https:// doi.org/10.1016/j.catcom.2009.04.009

Biresaw, G., Bantchev, G.B. Tribological properties of biobased ester phosphonates. J. Am. Oil Chem. Soc., 90, 891-902 (2013). https://doi.org/10.1007/ s11746-013-2232-1

Campanella, A., Fontanini, C., Baltanás, M.A. High yield epoxidation of fatty acid methyl esters with performic acid generated in situ. Chem. Eng. J., 144, 466-475 (2008). https://doi.org/10.1016/j. cej.2008.07.016

Carvalho, M.S., Mendonça, M.A., Pinho, D.M.M., Resck, I.S., Suarez, P.A.Z. Chromatographic analyses of fatty acid methyl esters by HPLCUV and GC-FID. J. Braz. Chem. Soc., 23, 763769 (2012). https://doi.org/10.1590/S010350532012000400023

Cheng, J., Qiu, Y., Huang, R., Yang, W., Zhou, J., Cen, K. Biodiesel production from wet microalgae by using graphene oxide as solid acid catalyst. Bioresour. Technol., 221, 344-349 (2016). https:// doi.org/10.1016/j.biortech.2016.09.064

Dhakshinamoorthy, A., Alvaro, M., Concepción, P., Fornés, V., Garcia, H. Graphene oxide as an acid catalyst for the room temperature ring opening of epoxides. Chem. Commun., 48, 5443-5445 (2012). https://doi.org/10.1039/c2cc31385e

Diciccio, A.M., Coates, G.W. Ring-opening copolymerization of maleic anhydride with epoxides: A chain-growth approach to unsaturated polyesters. J. Am. Chem. Soc., 133, 10724-10727 (2011). https://doi.org/10.1021/ja203520p

Dreyer, D.R., Jia, H.P., Bielawski, C.W. Graphene oxide: A convenient carbocatalyst for facilitating oxidation and hydration reactions. Angew. Chemie - Int. Ed., 49, 6813-6816 (2010). https://doi. org/10.1002/anie. 201002160

Gao, Y., Ma, D., Wang, C., Guan, J., Bao, X. Reduced Graphene Oxide as Catalyst for Hydrogenation of Nitrobenzene. Chem. Commun., 47, 2432-2434 (2011). https://doi.org/10.1039/C0CC04420B

Garg, B., Bisht, T., Ling, Y.C. Graphene-based nanomaterials as heterogeneous acid catalysts: A comprehensive perspective. Molecules, 19, 14582-14614 (2014). https://doi.org/10.3390/ molecules190914582

Guo, Y., Chang, B., Wen, T., Zhao, C., Yin, H., Zhou, Y., Wang, Y., Yang, B., Zhang, S. One-pot synthesis of graphene/zinc oxide by microwave irradiation with enhanced supercapacitor performance. RSC Adv., 6, 19394-19403 (2016). https://doi.org/10.1039/ C5RA24212F
Huang, Z., Liu, G., Kang, F. Glucose-Promoted ZnBased Metal - Organic Framework / Graphene Oxide Composites for Hydrogen Sul fi de Removal. ACS Appl. Mater. Interfaces, 4, 4942-4947 (2012). https://doi.org/10.1021/am3013104

Hummers, W.S., Offeman, R.E. Preparation of Graphitic Oxide. J. Am. Chem. Soc., 80, 1339 (1958). https://doi.org/10.1021/ja01539a017

Jacintho, G.V.M., Brolo, A.G., Corio, P., Suarez, P. a Z., Rubim, J.C. Structural Investigation of MFe 2 $\mathrm{O} 4(\mathrm{M}=\mathrm{Fe}, \mathrm{Co})$ Magnetic Fluids. J. Phys. Chem. C, 113, 7684-7691 (2009). https://doi.org/10.1021/ jp9013477

Jia, H.P., Dreyer, D.R., Bielawski, C.W., C-H oxidation using graphite oxide. Tetrahedron, 67, 4431-4434 (2011). https://doi.org/10.1016/j.tet.2011.02.065

Joonwichien, S., Yamasue, E., Okumura, H., Ishihara, K.N. Effect of Static Magnetic Field on Photocatalytic Degradation of Methylene Blue over $\mathrm{ZnO}$ and $\mathrm{TiO}_{2}$ Powders. Appl. Magn. Reson., 42, 17-28 (2012). https://doi.org/10.1007/s00723011-0270-0

Li, B., Liu, T., Wang, Y., Wang, Z. ZnO/grapheneoxide nanocomposite with remarkably enhanced visible-light-driven photocatalytic performance. J. Colloid Interface Sci., 377, 114-121 (2012). https:// doi.org/10.1016/j.jcis.2012.03.060

Madankar, C.S., Dalai, A.K., Naik, S.N. Green synthesis of biolubricant base stock from canola oil. Ind. Crops Prod., 44, 139-144 (2013). https:// doi.org/10.1016/j.indcrop.2012.11.012

Marso, T.M.M., Kalpage, C.S., Udugala-Ganehenege, M.Y. Metal modified graphene oxide composite catalyst for the production of biodiesel via preesterification of Calophyllum inophyllum oil. Fuel, 199, 47-64 (2017). https://doi.org/10.1016/j. fuel.2017.01.004

McNutt, J., He, Q.S. Development of biolubricants from vegetable oils via chemical modification. J. Ind. Eng. Chem., 36, 1-12 (2016). https://doi. org/10.1016/j.jiec.2016.02.008

Min, S., Lu, G. Dye-sensitized reduced graphene oxide photocatalysts for highly efficient visiblelight-driven water reduction. J. Phys. Chem. C, 115, 13938-13945 (2011). https://doi.org/10.1021/ jp203750z

Moharram, A.H., Mansour, S.A., Hussein, M.A., Rashad, M. Direct precipitation and characterization of $\mathrm{ZnO}$ nanoparticles. J. Nanomater., 2014, 20-25 (2014). https://doi.org/10.1155/2014/716210

Nasrollahzadeh, M., Jaleh, B., Jabbari, A. Synthesis, characterization and catalytic activity of graphene oxide/ZnO nanocomposites. RSC Adv., 4, 36713-36720 (2014). https://doi.org/10.1039/ C4RA05833J 
Navalón, S., Herance, J.R., Álvaro, M., García, H. General aspects in the use of graphenes in catalysis. Mater. Horizons, 5, 363-378 (2018). https://doi. org/10.1039/C8MH00066B

Nicolau, A., Samios, D., Piatnick, C.M.S., Reiznautt, Q.B., Martini, D.D., Chagas, A.L. On the polymerisation of the epoxidised biodiesel: The importance of the epoxy rings position, the process and the products. Eur. Polym. J., 48, 1266-1278 (2012). https://doi.org/10.1016/j. eurpolymj.2012.04.013

Nie, Y., Wang, W.N., Jiang, Y., Fortner, J., Biswas, P. Crumpled reduced graphene oxide-amine-titanium dioxide nanocomposites for simultaneous carbon dioxide adsorption and photoreduction. Catal. Sci. Technol., 6, 6187-6196 (2016). https://doi. org/10.1039/C6CY00828C

Oliveira, J.S., Montalvão, R., Daher, L., Suarez, P.A.Z., Rubim, J.C. Determination of methyl ester contents in biodiesel blends by FTIR-ATR and FTNIR spectroscopies. Talanta, 69, 1278-1284 (2006). https://doi.org/10.1016/j.talanta.2006.01.002

Oliveira, R.S., Machado, P.M.A., Ramalho, H.F., Rangel, E.T., Suarez, P.A.Z. Acylation of epoxidized soybean biodiesel catalyzed by $\mathrm{SnO} /$ A12O3and evaluation of physical chemical and biologic activity of the product. Ind. Crops Prod., 104, 201-209 (2017). https://doi.org/10.1016/j. indcrop.2017.04.049

Ramalho, H.F., Di Ferreira, K.M.C., Machado, P.M.A., Oliveira, R.S., Silva, L.P., Prauchner, M.J., Suarez, P.A.Z. Biphasic hydroformylation of soybean biodiesel using a rhodium complex dissolved in ionic liquid. Ind. Crops Prod., 52, 211-218 (2014). https://doi.org/10.1016/j.indcrop.2013.10.023

Ruschel, C.F.C., Ferrão, M.F., Santos, F.P. dos, Samios, D. Otimização do Processo de Transesterificação em Duas Etapas para produção de biodiesel. Quím. Nova, 39, 267-272 (2016).

Sakthivel, T.S., Das, S., Pratt, C.J., Seal, S. One-pot synthesis of a ceria-graphene oxide composite for the efficient removal of arsenic species. Nanoscale, 9, 3367-3374 (2017). https://doi.org/10.1039/ C6NR07608D
Samper, M.D., Fombuena, V., Boronat, T., GarcíaSanoguera, D., Balart, R. Thermal and mechanical characterization of epoxy resins (ELO and ESO) cured with anhydrides. J. Am. Oil Chem. Soc., 89, 1521-1528 (2012). https://doi.org/10.1007/s11746-012-2041-y

Scala, J. La, Wool, R.P. The effect of fatty acid composition on the acrylation kinetics of epoxidized triacylglycerols. J. Am. Oil Chem. Soc., 79, 59-63 (2002). https://doi.org/10.1007/s11746-002-0435-4

Sharma, R.V., Dalai, A.K. Synthesis of biolubricant from epoxy canola oil using sulfated Ti-SBA-15 catalyst. Appl. Catal. B Environ., 142, 604-614 (2013). https://doi.org/10.1016/j. apcatb.2013.06.001

Sharma, R.V., Somidi, A.K.R., Dalai, A.K. Preparation and properties evaluation of biolubricants derived from canola oil and canola biodiesel. J. Agric. Food Chem., 63, 3235-3242 (2015). https://doi. org $/ 10.1021 /$ jf505825k

Sheng, Y., Tang, X., Peng, E., Xue, J. Graphene oxide based fluorescent nanocomposites for cellular imaging. J. Mater. Chem. B, 1, 512-521 (2013). https://doi.org/10.1039/C2TB00123C

Wang, A., Chen, L., Jiang, D., Yan, Z. Vegetable oil-based ionic liquid microemulsions and their potential as alternative renewable biolubricant basestocks. Ind. Crops Prod., 51, 425-429 (2013). https://doi.org/10.1016/j.indcrop.2013.09.039

Wang, H., Deng, T., Wang, Y., Cui, X., Qi, Y., Mu, X., Hou, X., Zhu, Y. Graphene oxide as a facile acid catalyst for the one-pot conversion of carbohydrates into 5-ethoxymethylfurfural. Green Chem., 15, 23792383 (2013). https://doi.org/10.1039/c3gc41109e

Wang, J., Li, H., Zhang, R., Shi, X., Yi, J., Wang, J., Huang, Q., Yang, W. Highly active copolymerization of ethylene and $\mathrm{N}$-acetyl-O-( $\omega$-alkenyl)-L-tyrosine ethyl esters catalyzed by titanium complex. Polymers (Basel), 8, 1-12 (2016). https://doi. org/10.3390/polym8030064

Zhang, Q., He, Y.Q., Chen, X.G., Hu, D.H., Li, L.J., Yin, T., Ji, L.L., Structure and photocatalytic properties of TiO2-Graphene Oxide intercalated composite. Chinese Sci. Bull., 56, 331-339 (2011). https://doi.org/10.1007/s11434-010-3111-x 
